\title{
EL PROCESO DE ACTUALIZACIÓN DEL CÓDIGO DE PLANEAMIENTO URBANO. LA RECIENTE EXPERIENCIA EN LA CIUDAD DE CORRIENTES
}

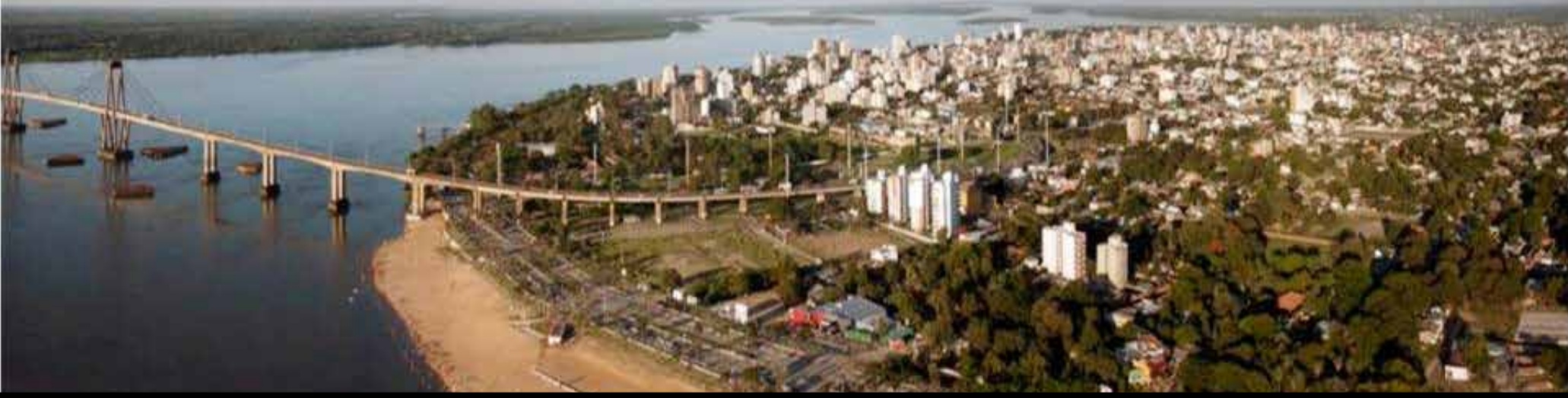




\section{EL PROCESO DE ACTUALIZACIÓN DEL CÓDIGO DE PLANEAMIENTO URBANO.}

LA RECIENTE EXPERIENCIA EN LA CIUDAD DE CORRIENTES

\section{PALABRAS CLAUE}

Código de Planeamiento Urbano; ciudad de Corrientes; actualización.

\section{RESUMEN}

Uno de los objetivos principales de la actual gestión municipal ha sido promover el proceso de actualización y adecuación del marco normativo urbano de nuestra ciudad, el cual llevaba un retraso considerable. Si bien en los últimos años se han ido incorporando algunas ordenanzas con modificaciones parcializadas, estas fueron intervenciones aisladas sin una mirada integral sobre la ciudad; por eso la primera cuestión fue poder definir y pautar los lineamientos estratégicos generales para el desarrollo futuro de la ciudad, y a partir de dicho marco de referencia poner en marcha las nuevas normativas que se adecuen a su desarrollo y crecimiento recientes y que acompañen además el importante volumen de obras de infraestructuras realizadas desde el año 2010.

En este trabajo conjunto, llevado a cabo con la participación y colaboración de los diversos actores urbanos y el equipo técnico de la Secretaría de Planeamiento Urbano, se logró revisar y actualizar aproximadamente el $75 \%$ de área urbana de la ciudad (distritos urbanos) y se produjo la tercera actualización integral del CPU en los últimos treinta años.

\section{KEYWORDS}

Urban Planning Code, Corrientes city, upgrade.

\section{ABSTRACT}

One of the main objectives of the current municipal management has been to promote the process of updating and adapting the urban regulatory framework of our city, which was considerably delayed. Although, in recent years, some Ordinances have been incorporated with biased modifications, these were isolated interventions without a comprehensive view of the City, hence the first question has been to define and guide the general Strategic Guidelines for future development from the city; and based on this framework implement the new appropriate regulations to the development and recent growth of the city, accompanying the important volume of infrastructure works, carried out since 2010 to this part. In this joint work, carried out with the participation and collaboration of the various urban actors and the technical team of the Secretary of Urban Planning, it was possible to review and update approximately $75 \%$ of urban area of the city (urban districts), occurring thus the third integral update of the Code of Urban Planning in the last thirty years. 


\section{MEMORIA DESCRIPTIVA}

Los continuos cambios que se dan en la ciudad, producto de la expansión y renovación urbanas, hacen imprescindible actualizar el marco normativo atendiendo a las nuevas necesidades de desarrollo y equilibrio de intereses, con una reglamentación adecuada, destinada a reglar el uso del suelo, la red vial, la localización de actividades productivas, la preservación de áreas de interés histórico, cultural, natural y paisajístico y la distribución coherente de la edificación regulando su densidad.

Resulta conveniente que toda modificación se elabore no solo con la participación de funcionarios municipales idóneos en la problemática, sino también con la colaboración de aquellos actores sociales directamente involucrados en el desarrollo de la ciudad. Respondiendo a esta idea, la Municipalidad de la Ciudad de Corrientes creó la Comisión Permanente de Revisión del Código de Planeamiento Urbano, por Resolución N. ${ }^{\circ}$ 2472/06. Está conformada por las áreas municipales que atienden la problemática urbana y por instituciones como el Consejo Profesional de la Ingeniería, Arquitectura y Agrimensura de la Provincia de Corrientes, la Sociedad de Arquitectos de Corrientes, la Cámara Inmobiliaria de Corrientes, el Colegio de Martilleros de Corrientes, el Instituto de Viviendas de la Provincia de Corrientes y la Facultad de Arquitectura y Urbanismo de la Universidad Nacional del Nordeste.

La Comisión Permanente de Revisión del Código de Planeamiento Urbano tiene como objetivo analizar y proponer actualizaciones y/o modificaciones al Código de Planeamiento Urbano de la Ciudad de Corrientes, que serán elevadas al DEM como

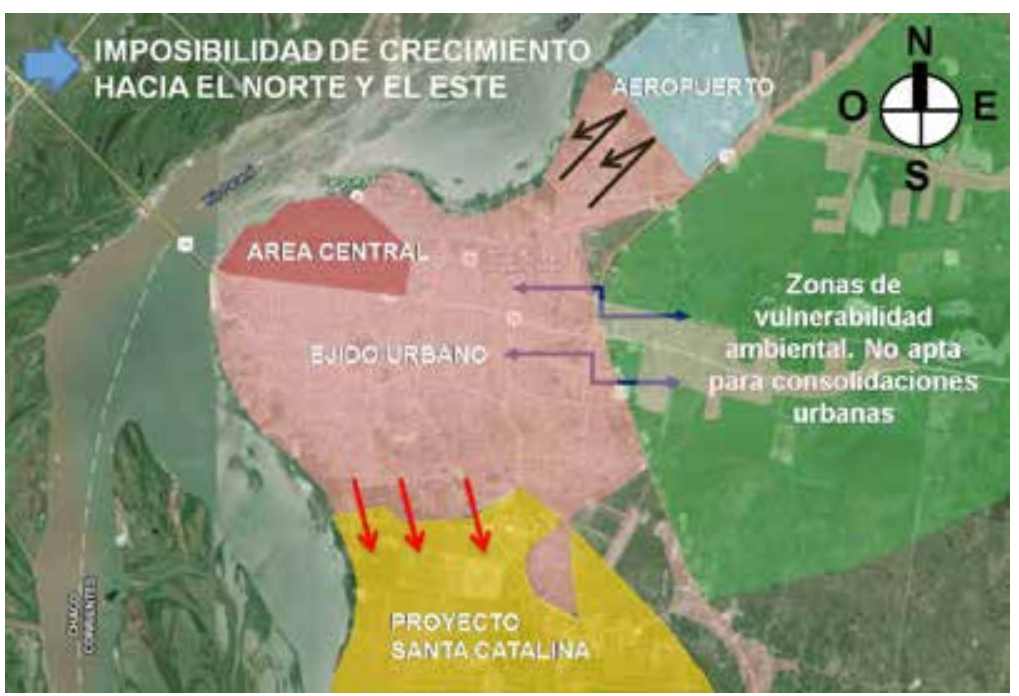

Proyecto de Ordenanza para su consideración y remisión al HCD. La metodología de trabajo consiste en la actualización del código por distritos; si bien los temas se abordan integralmente, los proyectos refieren a distritos particulares de la zonificación. De esta manera se definieron las temáticas prioritarias que tratar y se inició el trabajo de actualización normativa.

Todos los proyectos de modificaciones al CPU propuestos se enmarcan en los Lineamientos Estratégicos de Desarrollo Urbano del municipio, que pretenden dar cuenta de los contenidos mínimos de un Plan Urbano para la Ciudad de Corrientes, y expresan a grandes rasgos un "Proyecto de Ciudad" que sirva de encuadre y fundamento a los instrumentos de acción, tales como los programas y proyectos y la actualización de las normas del Código de Planeamiento Urbano.

\section{Los lineamientos estratégicos definidos son los siguientes:}

\section{Estructuración de la ciudad en} su escala microrregional

La consideración de la ciudad como parte de un sistema metropolitano y regional, en el cual desarrolla un rol particular que es necesario identificar para redefinirlo o fortalecerlo según los objetivos propuestos.

Gráfico 1. Situación territorial ciudad de Corrientes 
El sistema regional se entiende así como una red de núcleos urbanos de distintas jerarquías relativas en interrelación con las áreas tributarias o ámbitos intermedios, a los cuales brindan servicios, que debiera dar cuenta de las relaciones económicas de la región.

\section{Estrategia de crecimiento} urbanoy ordenamiento del suelo Una de las cuestiones más importantes es la definición del modo de crecimiento de la ciudad y los modos de ocupación del suelo, entendiéndolo como recurso urbano, productivo y ambiental. La estrategia se plantea desdeun posicionamiento que atiende la problemática de la sostenibilidad, la cual se asocia a modelos de ciudad compacta con limites urbanos definidos, en contraposición a modelos dispersos que tienden a expandirse de manera acrítica y no planificada. Consiste en la extensión de la ciudad hacia el sur, de manera gradual y programada a mediano y largo plazo, asociada a las demandas existentes dentro de la trama consolidada y en articulación con procesos de consolidación del área urbana y con la densificación de determinados distritos de la ciudad.

La definición del eje sur para la extensión de la ciudad se ha venido planteando desde los primeros estudios y planes elaborados. Hacia el norte y hacia el este, la ciudad encuentra límites sustanciales: al norte, el aeropuerto internacional y al este, zonas de bañados que forman parte del sistema de cuencas del Riachuelo, el cual es imperativo preservary proteger por cuestiones ambientales - como es la protección de los sistemas naturales-y por la función que desempeña este conjunto de lagunas en el sistema hídrico de la ciudad y su entorno. La adquisición por parte del municipio del territorio del Ejército nacional transformó la relación de la ciudad con aquel sitio, ya que dejó de constituir un límite para su crecimiento y se convirtió en el territorio destinado a su expansión. El Proyecto Urbano Ambiental "Santa Catalina", localizado en estas tierras, es un plan integral elaborado como estrategia para conducir una expansión gradual buscando equilibrar los procesos de dispersión actuales e interviniendo en el mercado de suelo ofertándolo a precios asequibles.

Por otro lado, se plantean el completamiento y la consolidación de los espacios que se encuentran total o parcialmente vacantes dentro del

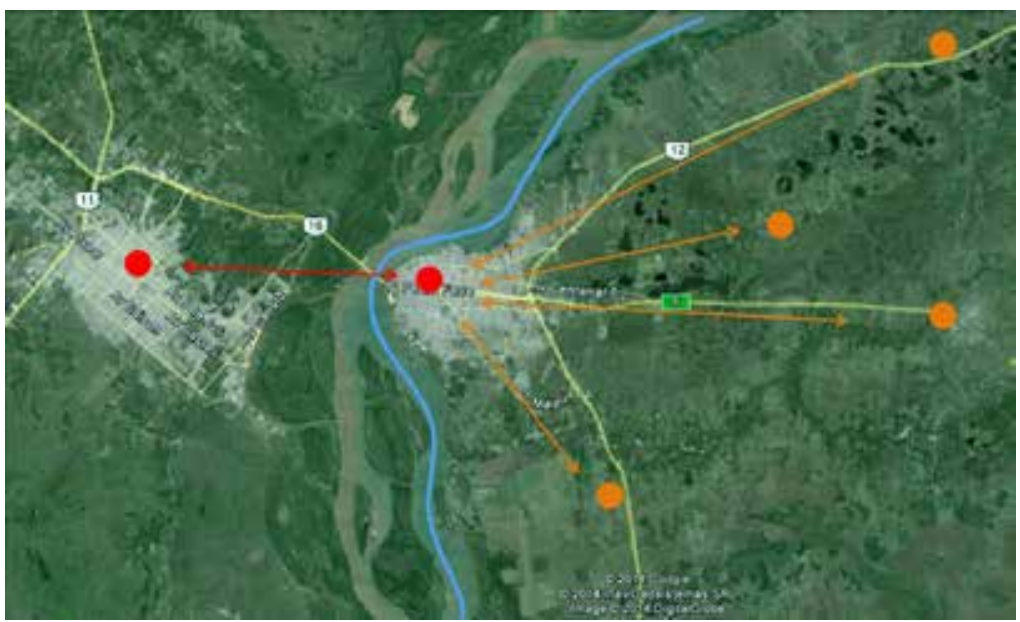

área urbana y la densificación de determinadaszonas en función de las características del territorio y la proyección de desarrollo de la ciudad y su escala, buscando la optimización en el aprovechamiento de los recursos. El proceso debería ir verificándose en el tiempo, mediante un programa a largo plazo que tenga en cuenta los datos demográficos prospectivos de crecimiento de la población.

Por su parte, la definición de los usos del suelo debería contribuir a lograr la mixtura e interrelación de las actividades en el territorio buscando diversidad y equilibrio urbanos.

\section{Estructuración urbana. Conectividad y movilidad}

La ciudad debería estructurarse según un sistema de centralidades jerárquicamente estratificadas, es decir, en centro y subcentros urbanos, interrelacionados. Para esto la optimización del sistema de red vial, el desarrollo de nuevos nodos urbanos con carácter central de jerarquías inferiores y la preservación de la centralidad urbana actual son necesarios, de manera de mantener la cohesión de la ciudad.

Las nuevas centralidades podrán proyectarse en zonas que hoy tienen la potencialidad en cuanto a localización, infraestructuras, y también en zonas vacantes o estratégicas en donde se prevea el desarrollo de planes especiales. A su vez, las avenidas primarias y secundarias podrían oficiar como estrategia de descentralización de los equipamientos comerciales de la ciudad, entre otros, ya que se han ido consolidando y abasteciendo de todas las infraestructuras necesarias.

En la estructuración de la ciudad, el sistema de espacios verdes públicos juega un rol de gran importancia; en consecuencia, deberian preverse las áreas destinadas a parques, para superarlafragmentación existenteen las reservas verdes buscando más equilibrio en la distribución de aquellos.

Gráfico 2. Lineamiento Estratégico Urbano 1 


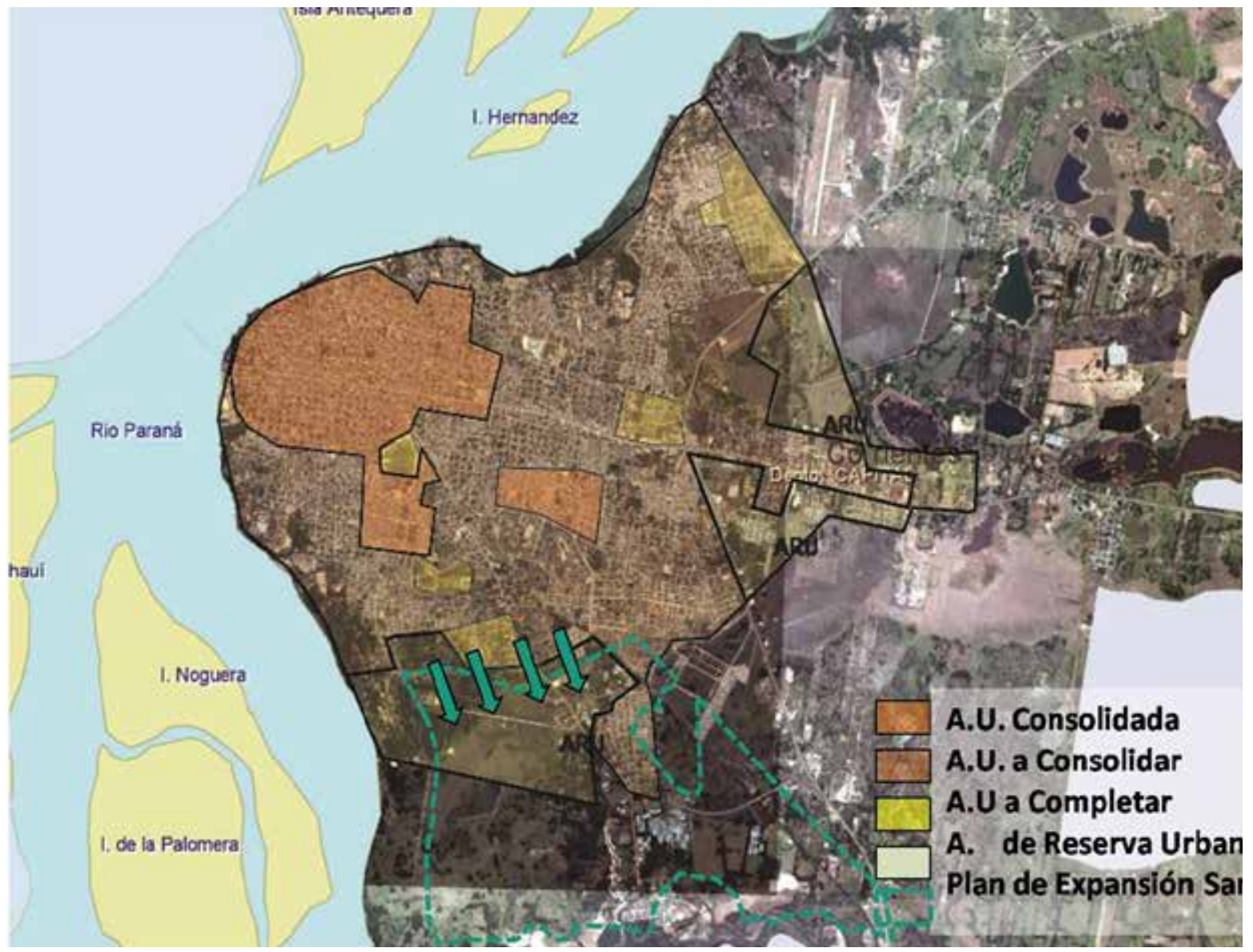

Gráfico 3. Lineamiento Estratégico Urbano 2

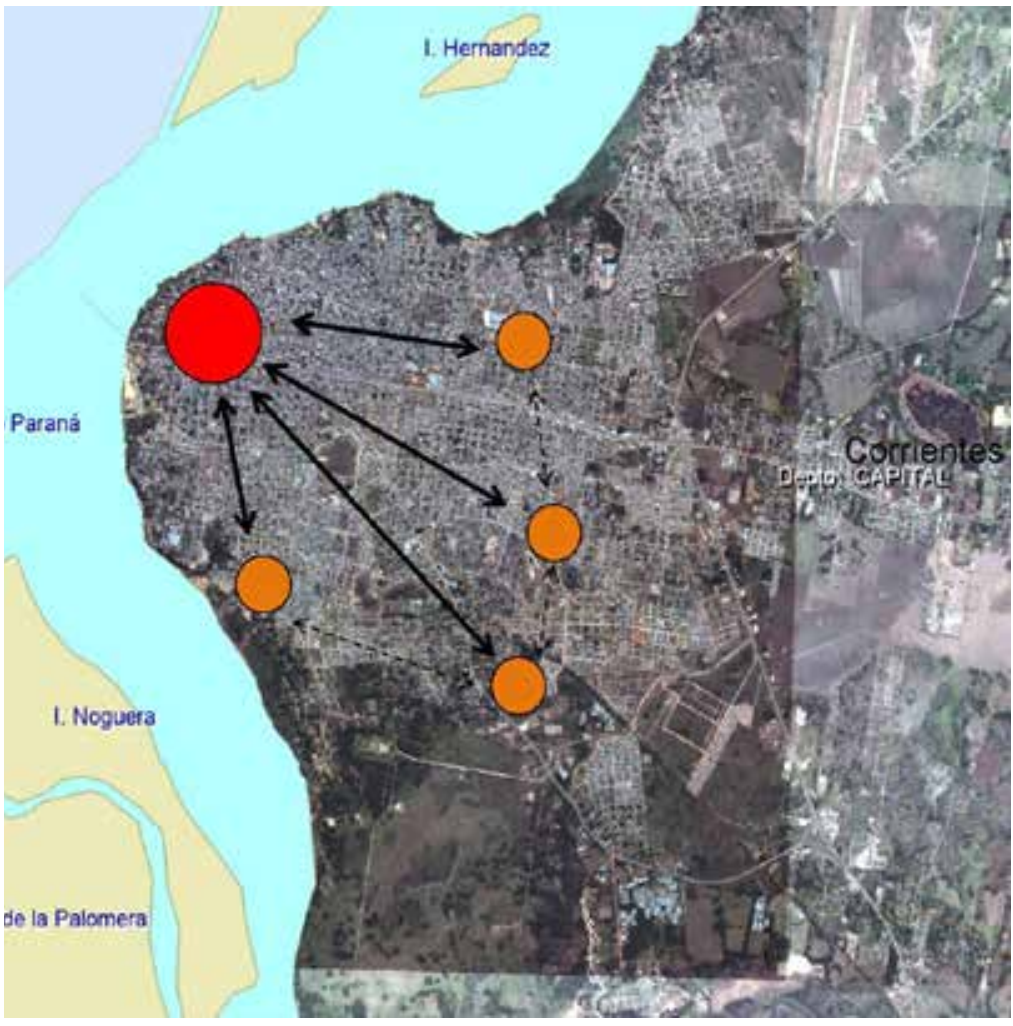

\section{Cualificación urbana}

Se plantea la cualificación o reconversión urbana como estrategia para poner en valor ciertas áreas ambientalmente degradadas de la ciudado aquellas con potencialidades para el desarrollo urbano, por sus características ambientales, arquitectónicas, o por su localización. Esto tiende a superar el desequilibrio existente producto de la localización casi exclusiva del gasto público y de la inversión privada en determinadas zonas de la ciudad. La estrategia para lograrlo es mediante planes o proyectos especiales, acompañados por la normativa pertinente.

Gráfico 4. Lineamiento

Estratégico Urbano 3 


\section{Gráfico 5 \\ Lineamiento Estratégico Urbano 4}

\section{Hábitat y el acceso al suelo}

Se entiende que el problema del hábitat en relación con el acceso al suelo es de una magnitud y complejidad que exceden al ámbito local, y se requieren políticas articuladas entre las diferentes escalas de gobierno para lograr soluciones adecuadas. Sin embargo, la gestión local debe delinear las políticas en materia de suelo, y uno de los planificación y gestión del territorio.

A su vez, los municipios deberian orientar el financiamiento de los proyectos y programas de mejoramiento de áreas socialmente vulnerables definiendo el orden de prioridades. instrumentos para hacerlo es la

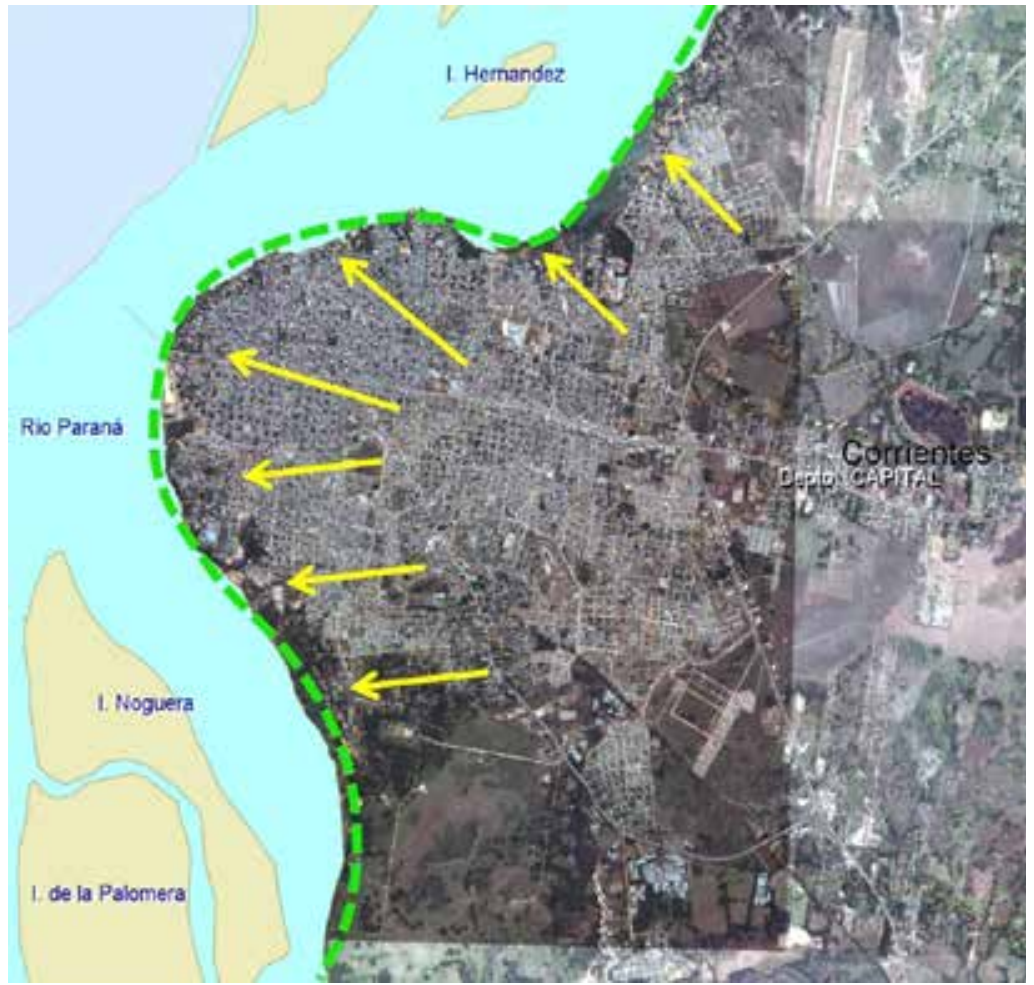

Gráfico 6. Lineamiento Estratégico Urbano 5

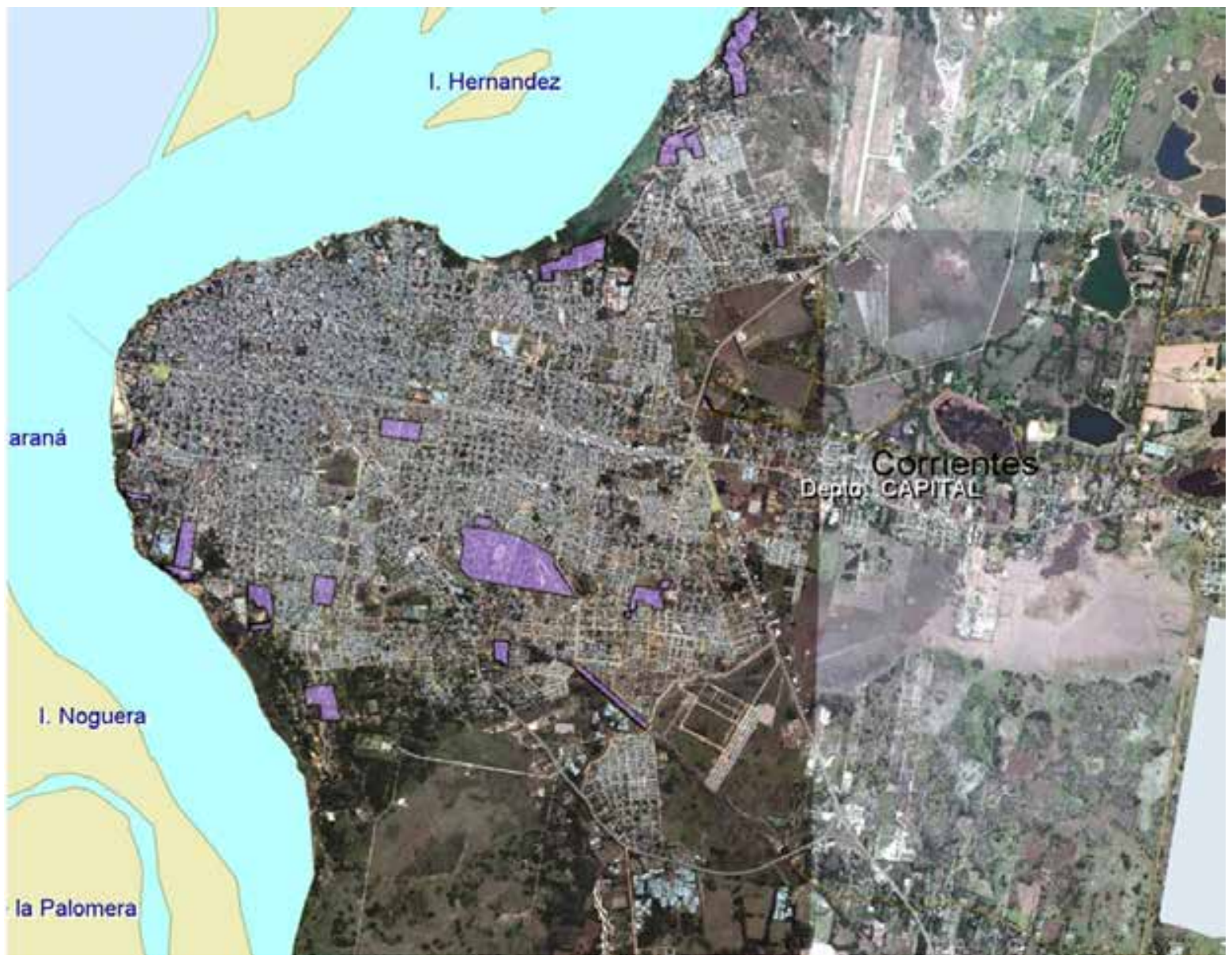




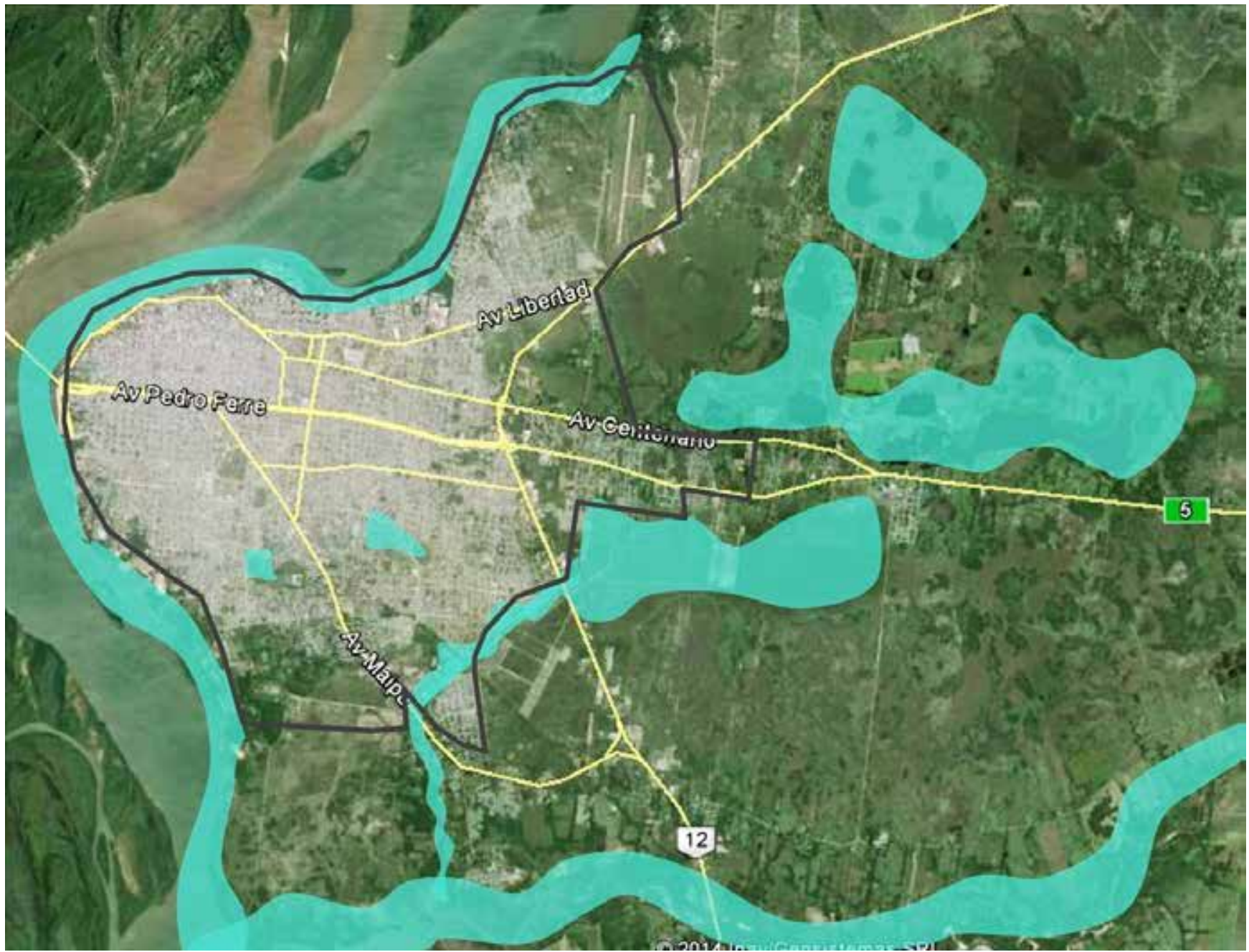

Gráfico 7. Lineamiento Estratégico Urbano 6

\section{Protección de los sistemas productivos y naturales}

Entendemos que el territorio urbano debe buscar mantener en el proceso de su desarrollo una situación de equilibrio con el entorno y con los sistemas en los que se encuentra inserto, sean estos territorios rurales o naturales. El concepto de ciudad compacta manifiesta la concientización de la necesidad de delimitar las urbes en su extensión, debido a la afec- tación que estas producen sobre el entorno no-urbano, para buscar cierto equilibrio entre sistema de ciudades, sistemas productivos rurales y sistemas naturales no antropizados.

La delimitación formal y física de la frontera urbano-rural es una herramienta que ha servido a la planificación de ciudades controlando su crecimiento extensivo y promoviendo modos más eficientes de crecimiento y financiación del desarrollo urbano. Por otra parte, es necesario pensar la protección y promoción de las actividades productivas no solo como abastecimiento de la población, sino como sustento económico al desarrollo de la ciudad, y exportar productos a otras ciudades para originar ingresos.

\section{Instrumentos de financiamiento urbano}

La ciudad puede considerarse un mecanismo de distribución de recursos a través de la localización de los equipamientos e infraestructuras, debido a que la existencia o la carencia de estos en el entorno generan diferentes oportunidades para el desenvolvimiento de quienes viven allí.

La elaboración de instrumentos de planificación y gestión en articulación público-privada, con el Estado local como promotor e inductor de la iniciativa privada, sobre el mero rol regulador, es una manera de captar sinergias que permitan generar recursos para las áreas más postergadas en urbanización, infraestructura y equipamientos. 


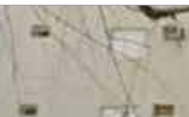

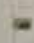

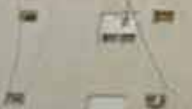

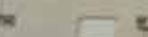

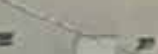

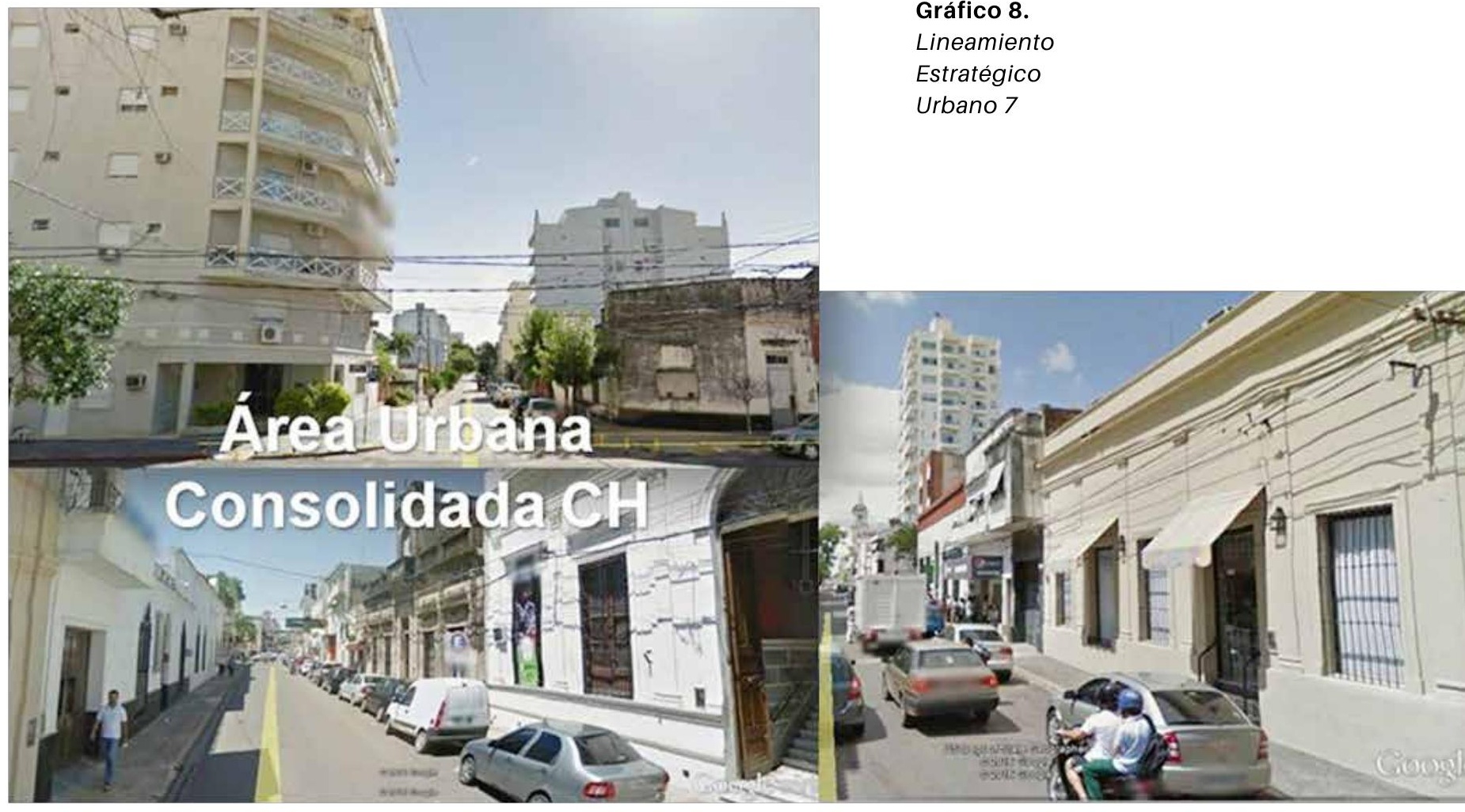

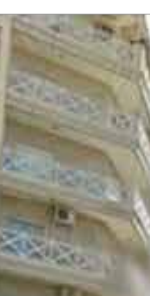

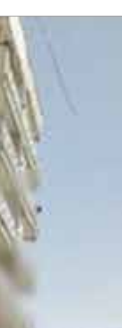
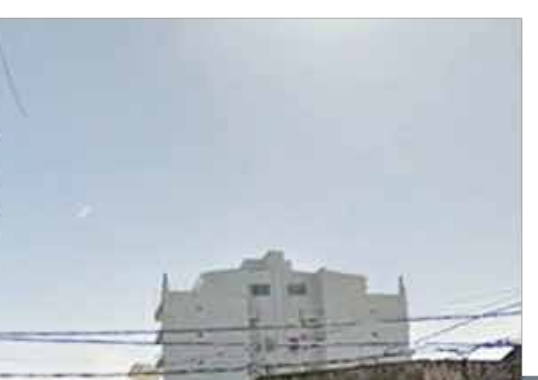

\section{Gráfico 8.}

Lineamiento

Estratégico

Urbano 7
Resultados del trabajoencomisión

En estos cuatro últimos años de trabajo encomisión (desde diciembre de 2013 a la fecha) se han logrado importantes avances en cuanto a la actualización del Código de Planeamiento Urbano. Se ha podido actualizar las dos terceras partes del territorio municipal, es decir, los anillos segundo y tercero del ejido urbano de la ciudad, zonas que a partir del alto desarrollo de las infraestructuras del área permitieron consolidar la mancha urbana y optimizar su capacidad de soporte de infraestructura. Como consecuencia de esto, se actualizaron los Distritos Residenciales $\mathbf{2}$ y 3, de densidad media y baja respectivamente, con estrecha relación con las actualizaciones de los Distritos de Equipamientos 1, que son aquellos de las avenidas principales del área urbana. También se incorporó otro Distrito de Equipamiento Mixto. A partir de las nuevas vías de interconexión barrial consolidadas en la ciudad, se generan estos nuevos distritos de carácter residencial y mixto, que vienen a atender la necesidad de descentralización de actividades del área central de la ciudad.

También se han propuesto modificaciones a los Distritos de Residenciales Plan, saneando una compleja situación de hecho que dejaba manchas aisladas de todo tipo de Planes Residenciales de Vivienda Social, sin posibilidad de crecimiento alguno. De la modificación resultó que algunos de ellos se incorporaron a los distritos residenciales en los cuales estaban inmersos, otros quedaron especificados con características ambientales particulares y otros con tipología edilicia particular debían tener otras condiciones para su crecimiento edilicio.

Además, en las áreas centrales de la ciudad, sehan propuesto actualizaciones en los Distritos Residenciales 1, de alta densidad, y se definieron no solo actualizaciones de capacidades constructivas, sino también la actualización de estacionamientos mínimos necesarios para atender la compleja problemática de la movilidad en el área central. En este orden también se propusieron actualizaciones en los Distritos Comerciales Centrales, y se redefinieron algunos usos permitidos en la zona, particularmente aquellos cuya magnitud y afluencia de visitantes hacen necesario que se localicen en áreas más aptas para el correcto desarrollo de estas actividades, para tender así a la descentralización comercial y administrativa de la ciudad.

Otra ordenanza elaborada por la comisión y aprobada por el Concejo Deliberante fue la actualización y recategorización de un Distrito Industrial en el sur de la ciudad, que había quedado inmerso en un distrito residencial y que nunca se había desarrollado como distrito industrial; por lo contrario, era un área netamente residencial. En este orden también se actualizó otro distrito residencial lindero al área central que estaba definido como de densidad media y a estas alturas era un distrito de densidad alta, con todos los servicios necesarios para su recategorización. 


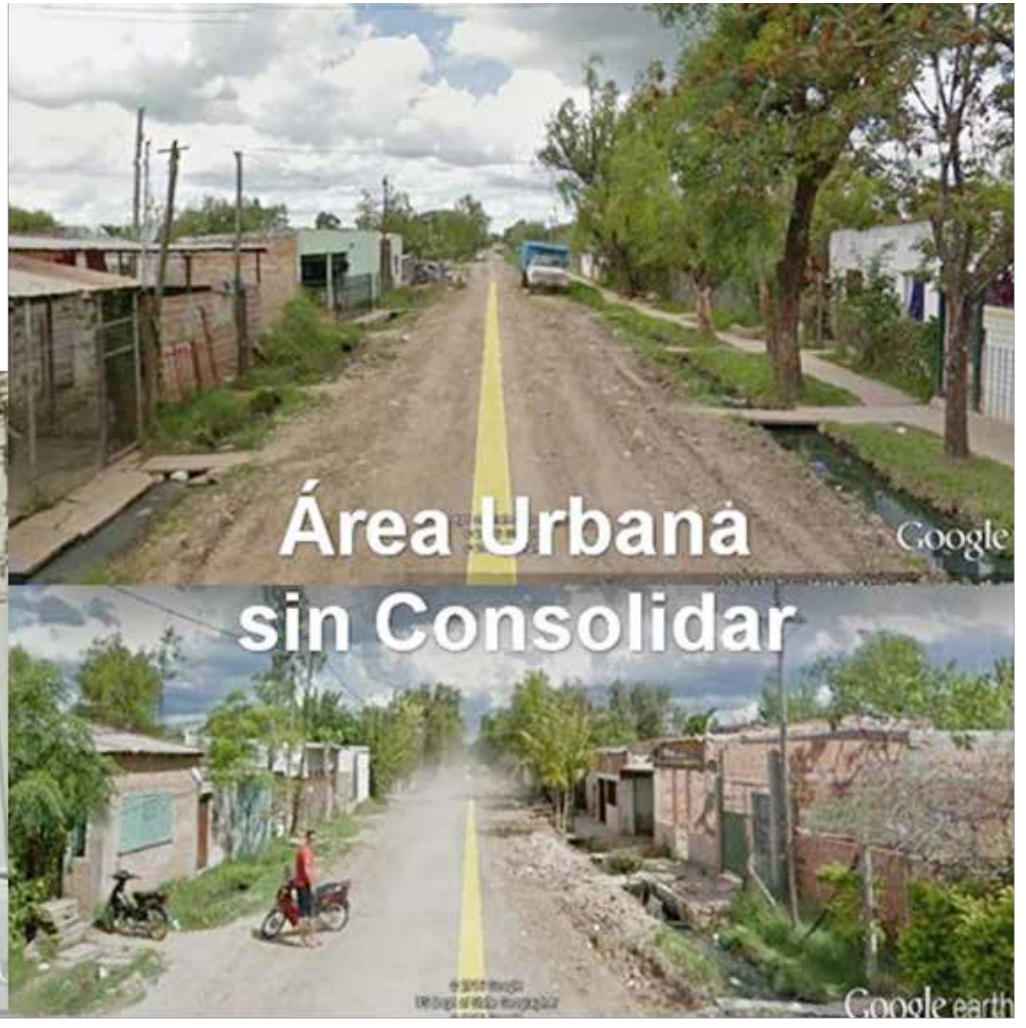

Otro punto importante que hace a la actualización del código en general es la modificación en cada uno de los distritos que se fueron actualizando de la Conformación del Espacio Urbano. Se propone que la profundidad de las edificaciones esté en función del lote, y se establece un porcentaje de superficie libre que no necesariamente se circunscribe al centro de manzana, ya que debe quedar un $20 \%$ de la longitud del lote de retiro de fondo y otro 10 a $15 \%$ que se puede distribuir en patios reglamentarios. Esto genera mayor flexibilidad a las edificaciones e iguala las exigencias para todos los lotes de la manzana. De esta manera se asegura un mayor porcentaje de superficie libre absorbente por manzana.

Además es importante remarcar que todos los proyectos elaborados en el trabajo de comisión fueron aprobados con el consenso de todos los integrantes de la comisión y las instituciones que ellos representan, y se los elevó al Honorable Concejo Deliberante para su tratamiento y aprobación, lo que les da una mayor legitimidad social a las ordenanzas aprobadas.

Las ordenanzas elaboradas en el marco de la comisión en estos años de trabajo son las que se detallan a continuación.

\section{ORDENANZAS APROBADAS}

- Ordenanza N. ${ }^{\circ} 6349$

Distrito Industrial 2 a Distrito Residencial 3.

Gráfico 9. Análisis Distrito

Industrial 2, actualización a Distrito Residencial 3

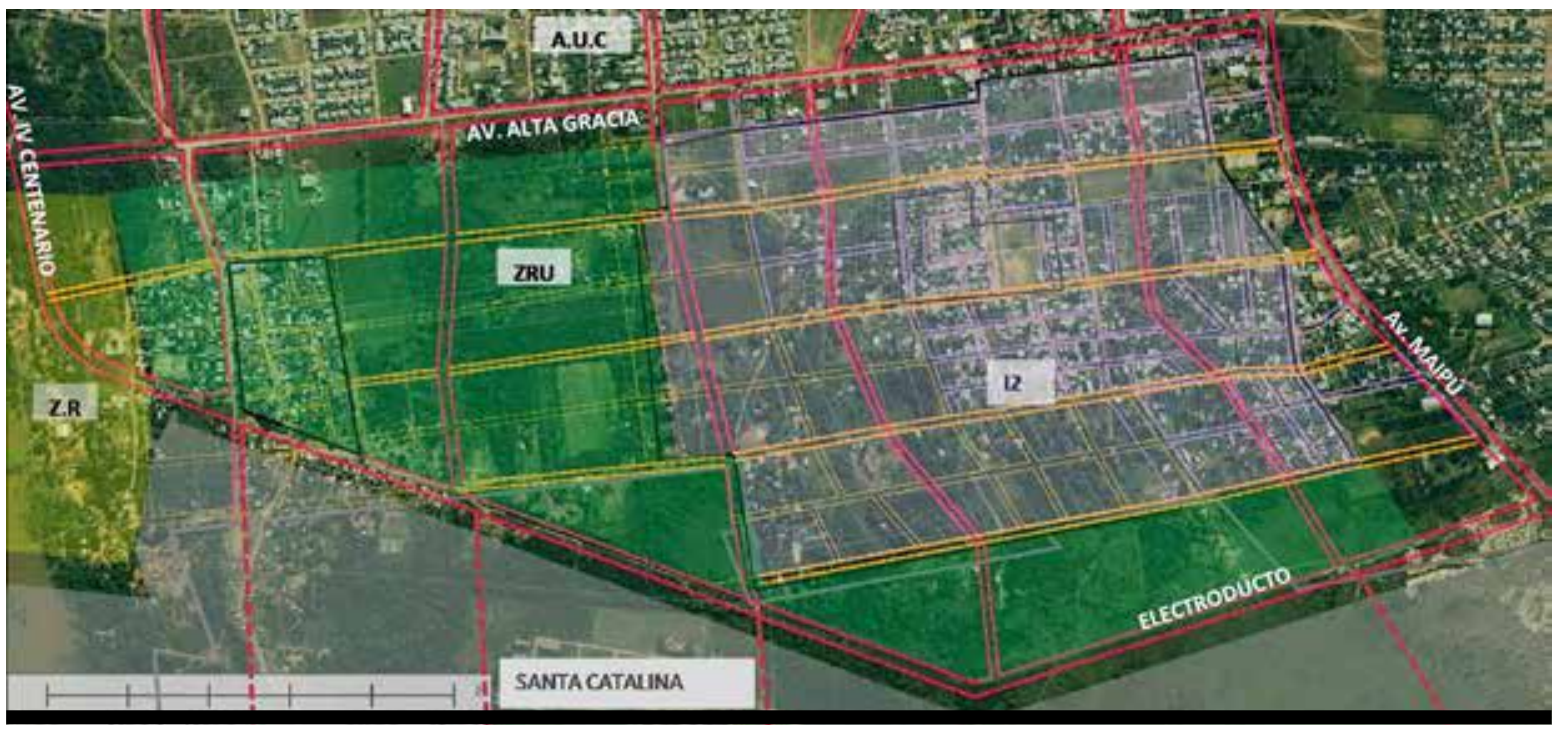


- Ordenanza N.ำ 6350

Distrito Residencial 2 (barrio Belgrano) a Distrito Residencial 1.
Gráfico 10. Análisis Distrito

Residencial 1 - barrio Belgrano

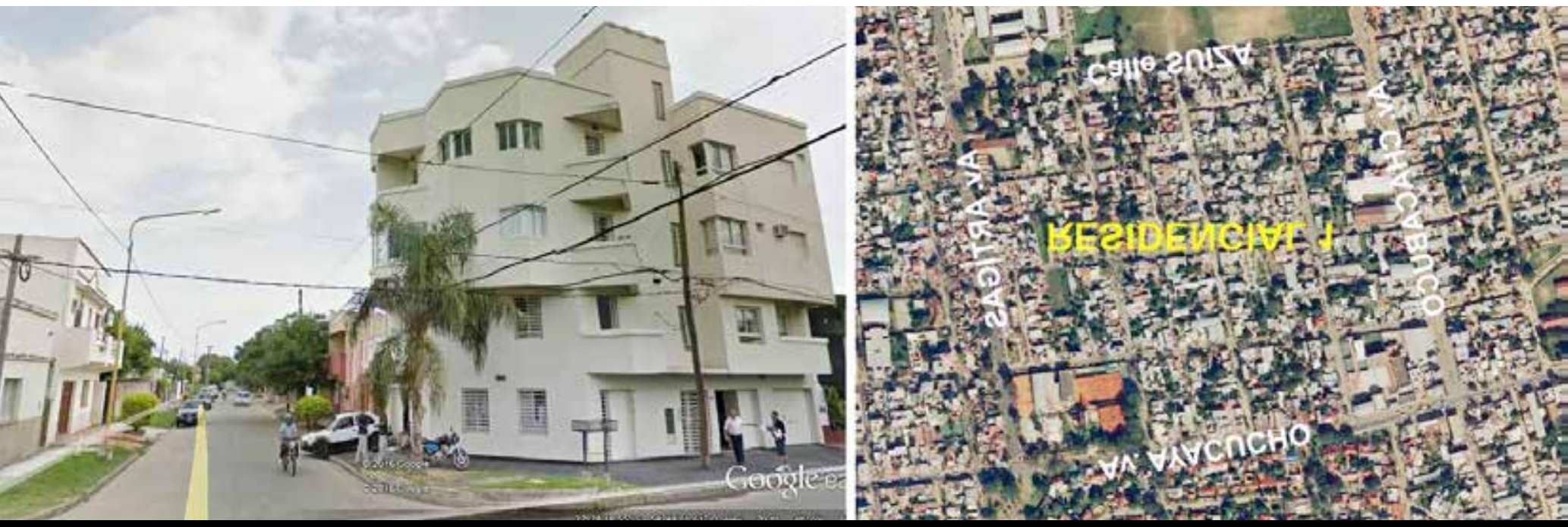

\section{- Ordenanza N. ${ }^{\circ} 6428$}

Distritos Residenciales 2 y 3.

*Residencial 2; se actualizan parámetros.

* Residencial 3 a Distrito Residencial 3.a. Desarrollo Prioritario

Gráfico 11. Análisis Distritos y Distrito Residencial 3.b. Desarrollo Diferido.

Residenciales 2 y 3

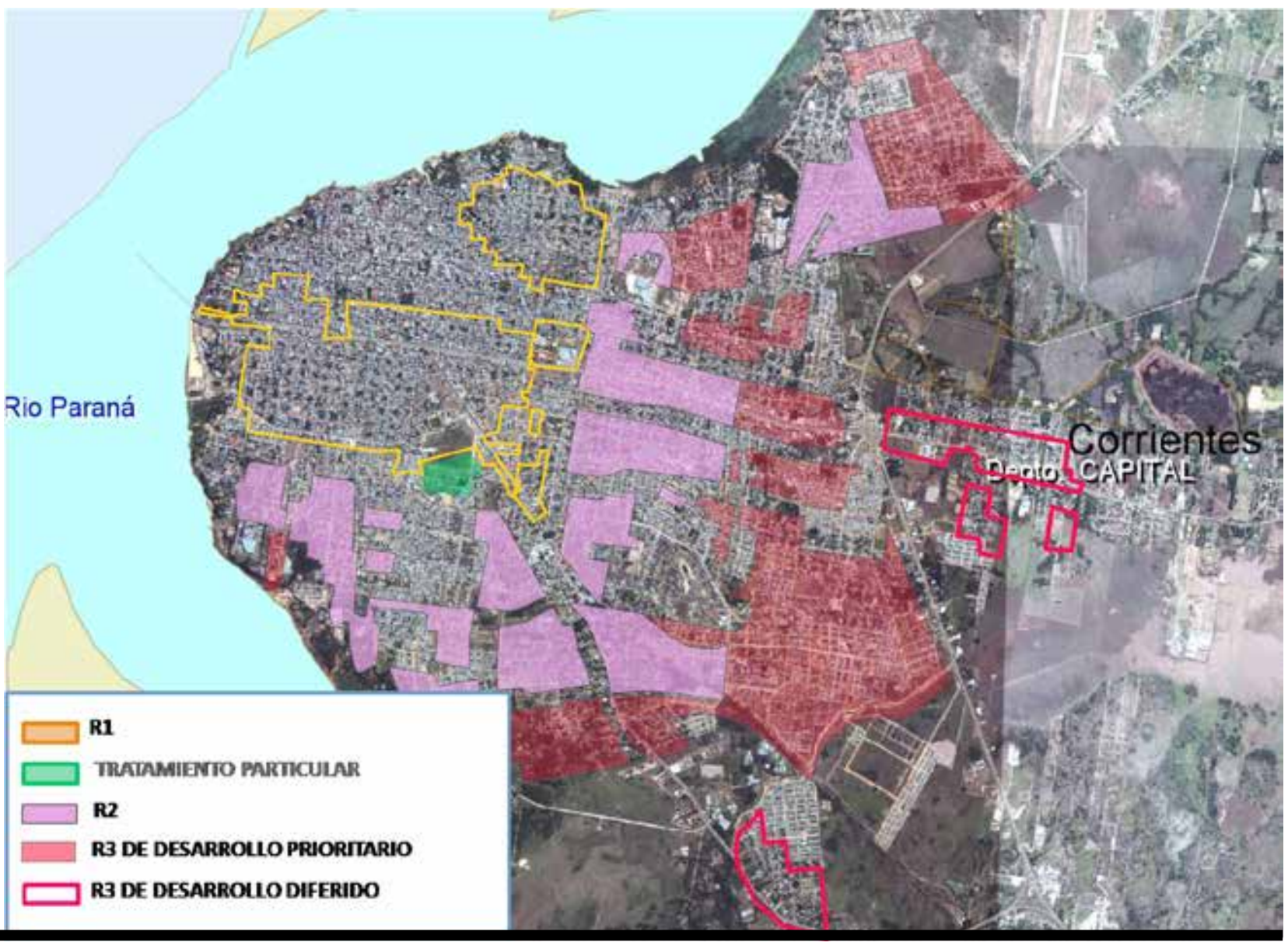


- Ordenanza N. ${ }^{\circ} 6417$

Gráfico 12. Análisis Distritos

Distritos Equipamiento E 1

Equipamientos 1 y Mixtos

*Se actualizan parámetros E1, Uso Comercial Predominante.

*Se definen EM, Uso Mixto - Comercial y Residencial.

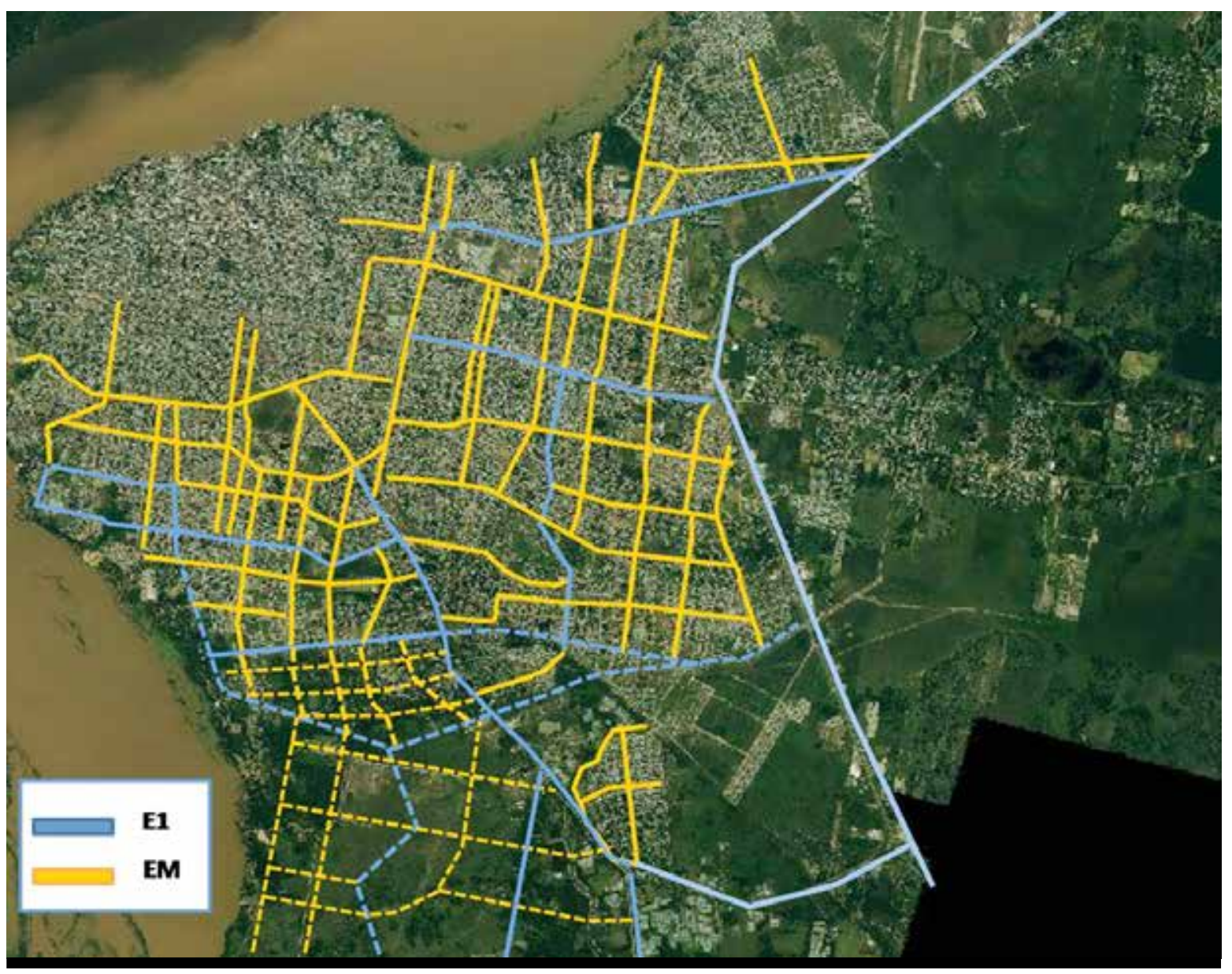

\section{PROYECTOS DE ORDENANZA}

Distrito Residencial 1; se actualizan parámetros.

Gráfico 13. Análisis Distrito Residencial 1

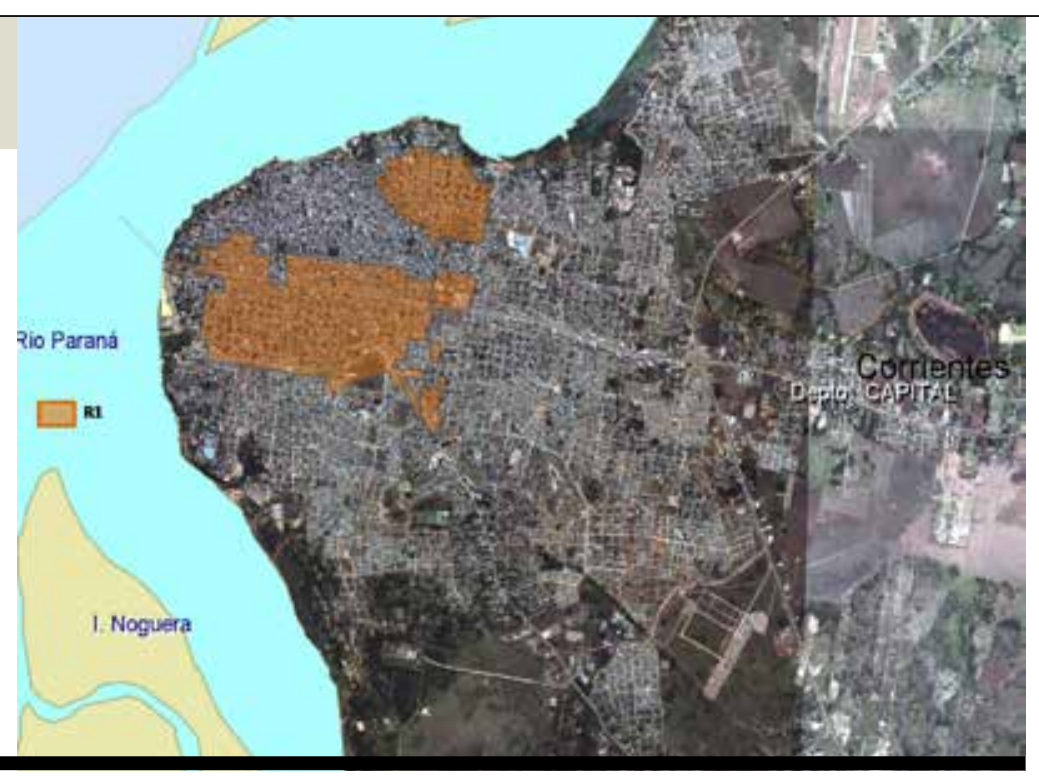




\section{Distrito Residencial Plan RP}

* Los que se incluyen en los distritos residenciales 2 y 3.

* Rp. Conjuntos Habitacionales para ejecutar.

* Rep. Conjunto habitacional barrio Yapeyú.

* Rpa. Conjuntos Habitacionales con Características Particulares.

*Rp b. Conjuntos Habitacionales tipología Dúplex.

*Rp c. Proyectos de Ordenamiento y Mejoramiento Urbano.

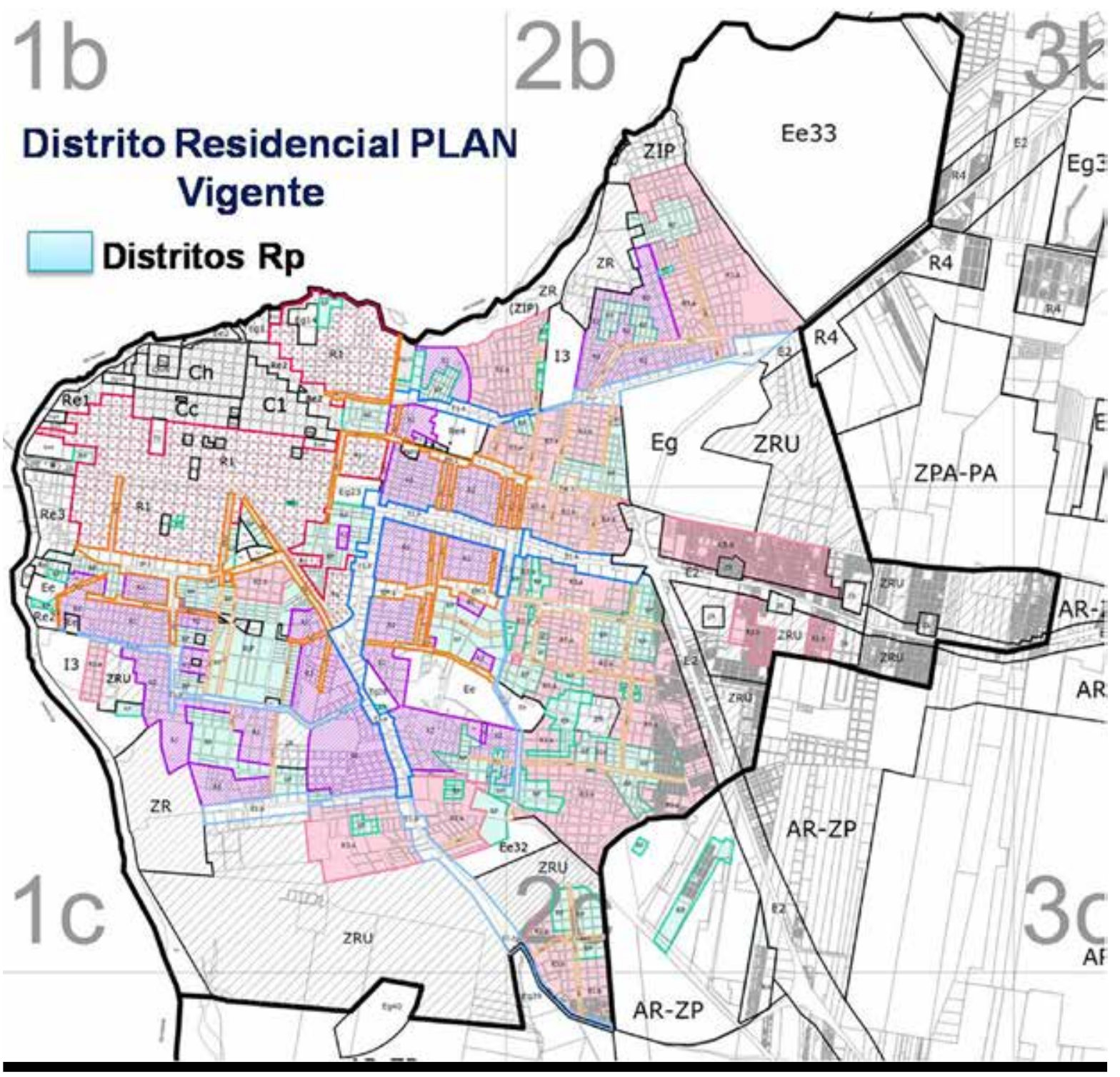

Gráfico 14. Análisis Distritos Residencial Plan - vigente 


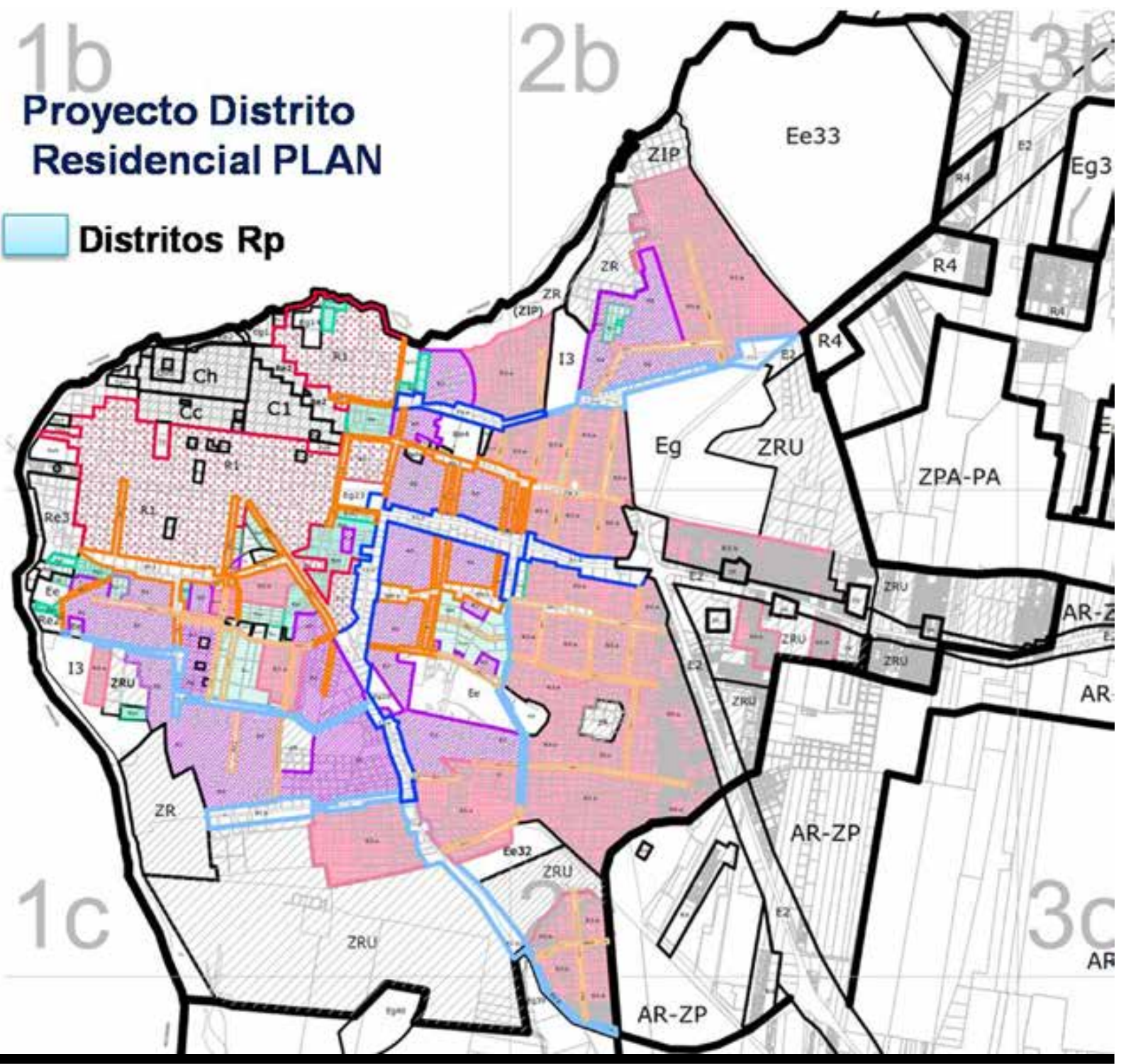

Gráfico 15. Análisis Proyecto

Distritos Residencial Plan 


\section{PROYECTOS DE ORDENANZA EN TRABAJO DE COMISIÓN}

* Distrito Central Comercial, CC y C1; se actualizan parámetros.

Gráfico 16. Análisis

Proyecto Distritos

Centrales

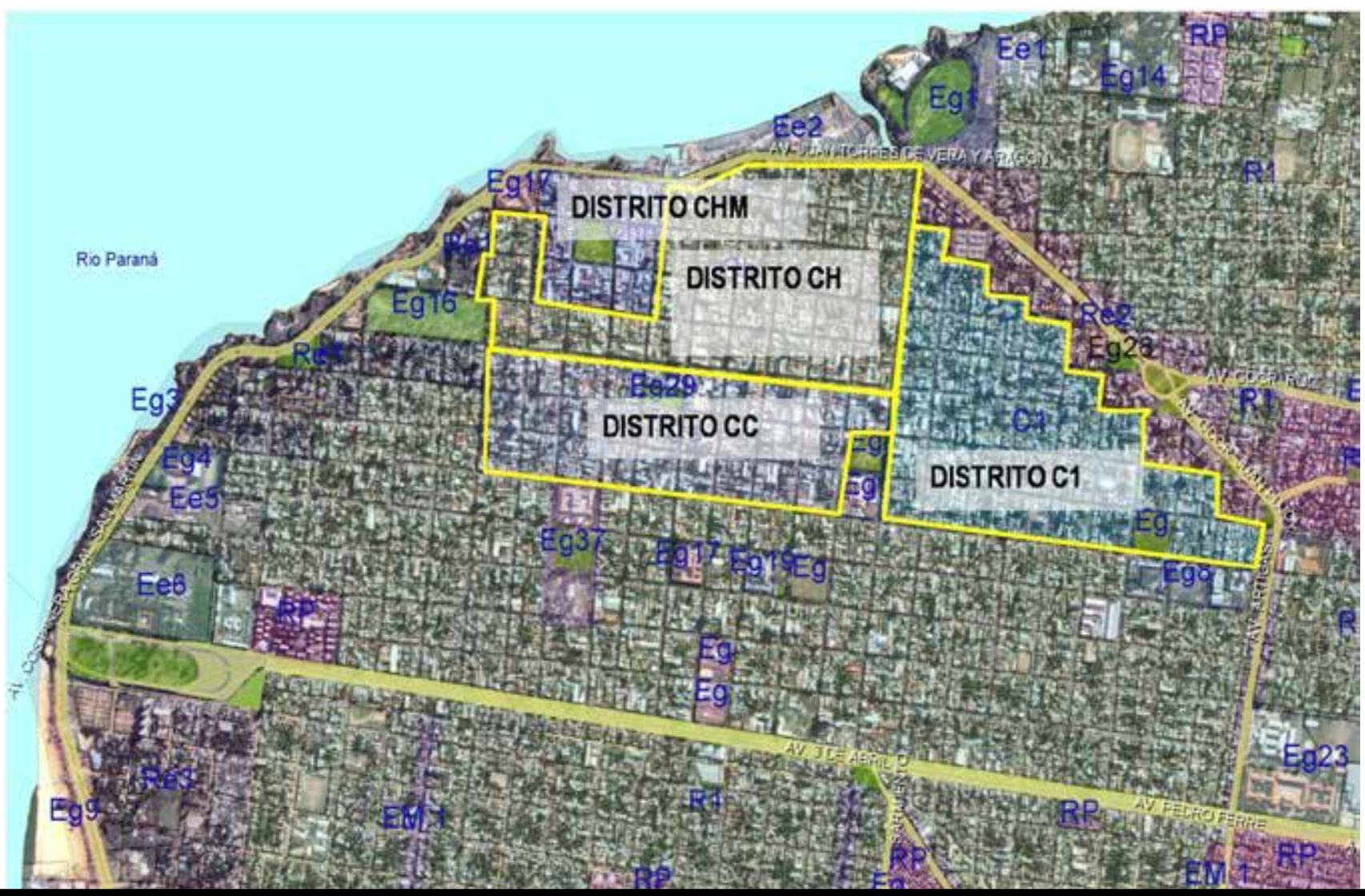

\section{REFLEXIONES FINALES}

El desarrollo planificado y ordenado de nuestras ciudades en general (Región NEA) y de la nuestra en particular presenta una raigambre y una tradición cultural relativamente recientes. Nuestro Código de Planeamiento Urbano tiene apenas treinta años de historia, y nuestra ciudad está próxima a cumplir 430 años de su fundación, y aunque esta información pudiera parecer "anecdótica" o poco relevante, lo cierto es que no solo el corpus normativo de nuestra ciudad es relativamente joven, sino que también -y esto es seguramente lo más importante- la conciencia ciudadana, urbana y política respecto del rol y la importancia de la Planificación Urbana y el apego o el respeto por las normas de urbanidad son todavía más recientes y frágiles. Ciertamente, esta situaciónestransversal a todas las clases sociales, e incluso a niveles institucionales.
En definitiva, la ciudad es una construcción social colectiva que nos incumbe a todos los ciudadanos, y en especial a quienes tenemos competencias y responsabilidades profesionales específicas. Los resultados logrados en este breve tiempo en términos de adecuación y actualización normativa han sido muy importantes; sin embargo, aún queda en agenda una serie demetaspendientes, que sería deseable continúen su desarrollo. 
*Predios del Exaeroclub, hoy Distrito Residencial 3. Se analizan parámetros particulares para este gran vacío urbano, hoy en el centro de la ciudad.
Gráfico 17. Análisis

Proyecto Distrito

Exaeroclub

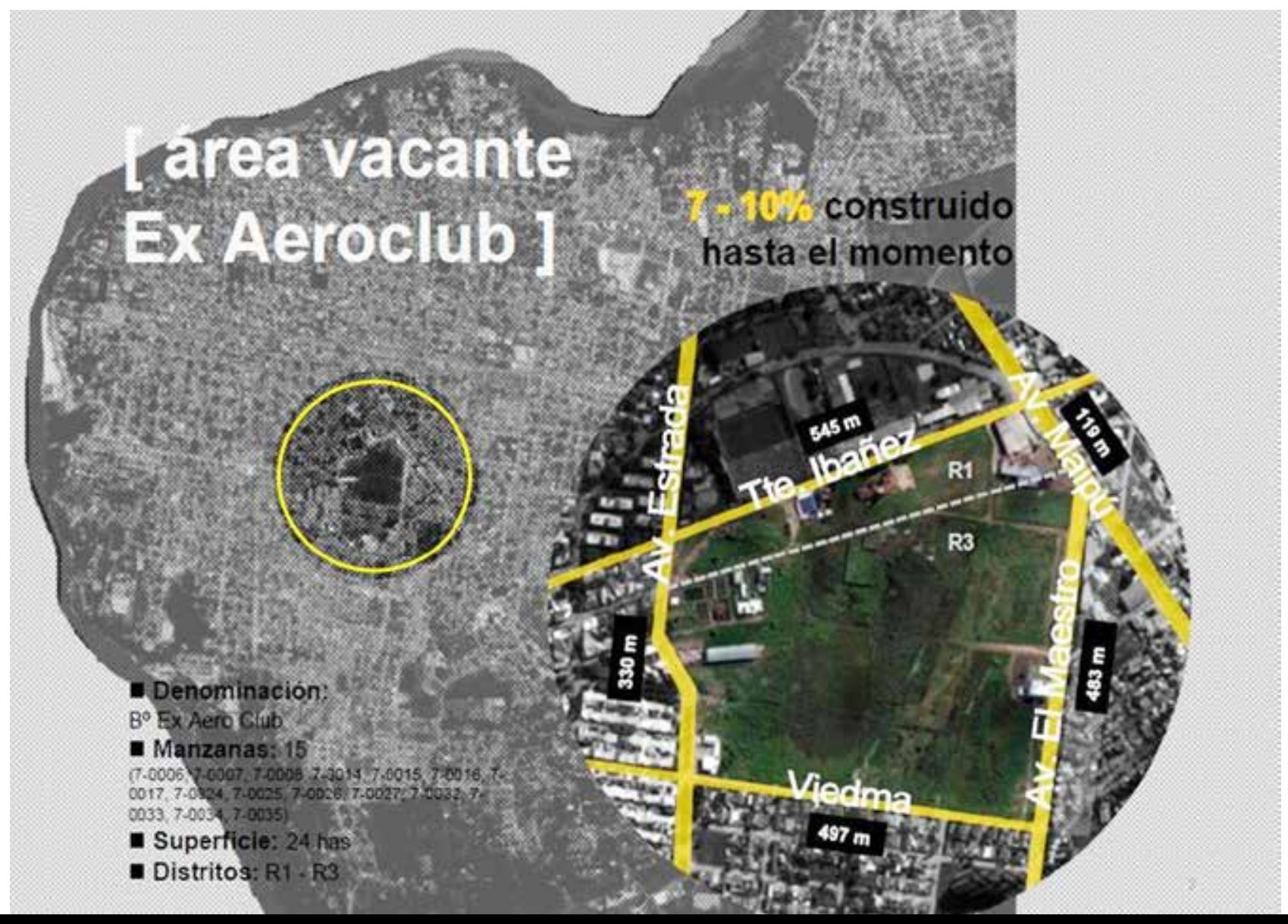

Por otra parte, el texto de una norma debe complementarse con la acción docente y de fiscalización municipal, tarea ardua que requiere una acción constantey permanente en todo el territorio de la ciudad. Probablemente el mayor desafío actual es sostener las políticas públicas de ordenamiento y planificación urbana y territorial en el tiempo. Esta tarea requiere conformar y consolidar un equipo multidisciplinar de profesionales altamente capacitados, bien remunerados y fundamentalmente comprometidos con la ciudad. Conformar y consolidar equipos de trabajo de esta naturaleza es una tarea ardua, pero sin duda todo ello no sería posible si no existiera la voluntad y decisión política de hacerlo, y este aspecto sigue siendo el componente más inestable: la clase política en general (al menos en nuestro contexto) apenas ha comenzado a tomar real conciencia de la importancia de promover y sostener políticas de planificación urbana y territorial sostenidas en el tiempo. Nuestro rol como técnicos y urbanistas es demostrar y convencer a quienes tienen el poder de decisión de la importancia y la necesidad de sostener esas políticas públicas. A diferencia de la arquitectura, la construcción y el desarrollo de las ciudades no tiene un solo autor, porque necesariamente es una construcción social colectiva, que por otra parte trasciende nuestras propias existencias: solo somos un pequeño eslabón en un largo proceso de decisiones y acciones colectivas. Claramente, el mayor desafío y a la vez la mayor debilidad de nuestra labor es ser capaces de sostener una mirada de largo plazo, que al mismo tiempo sea compatible y coherente con el accionar de medianoy corto plazo. 
